\title{
The most dangerous hospital or the most dangerous equation?
} Yu-Kang Tu*1,2 and Mark S Gilthorpe ${ }^{1}$

Address: ${ }^{1}$ Biostatistics Unit, Centre for Epidemiology and Biostatistics, University of Leeds, 30/32 Hyde Terrace, Leeds, LS2 9LN, UK and 2 Leeds Dental Institute, University of Leeds, Clarendon Way, Leeds, LS2 9LU, UK

Email: Yu-Kang Tu* - y.k.tu@leeds.ac.uk; Mark S Gilthorpe - m.s.gilthorpe@leeds.ac.uk

* Corresponding author

Published: 15 November 2007

BMC Health Services Research 2007, 7:185 doi:10.1 186/1472-6963-7-185

Received: II June 2007

Accepted: 15 November 2007

This article is available from: http://www.biomedcentral.com/1472-6963/7//85

(c) 2007 Tu and Gilthorpe; licensee BioMed Central Ltd.

This is an Open Access article distributed under the terms of the Creative Commons Attribution License (http://creativecommons.org/licenses/by/2.0), which permits unrestricted use, distribution, and reproduction in any medium, provided the original work is properly cited.

\begin{abstract}
Background: Hospital mortality rates are one of the most frequently selected indicators for measuring the performance of NHS Trusts. A recent article in a national newspaper named the hospital with the highest or lowest mortality in the 2005/6 financial year; a report by the organization Dr Foster Intelligence provided information with regard to the performance of all NHS Trusts in England.
\end{abstract}

Methods: Basic statistical theory and computer simulations were used to explore the relationship between the variations in the performance of NHS Trusts and the sizes of the Trusts. Data of hospital standardised mortality ratio (HSMR) of 152 English NHS Trusts for 2005/6 were reanalysed.

Results: A close examination of the information reveals a pattern which is consistent with a statistical phenomenon, discovered by the French mathematician de Moivre nearly 300 years ago, described in every introductory statistics textbook: namely that variation in performance indicators is expected to be greater in small Trusts and smaller in large Trusts. From a statistical viewpoint, the number of deaths in a hospital is not in proportion to the size of the hospital, but is proportional to the square root of its size. Therefore, it is not surprising to note that small hospitals are more likely to occur at the top and the bottom of league tables, whilst mortality rates are independent of hospital sizes.

Conclusion: This statistical phenomenon needs to be taken into account in the comparison of hospital Trusts performance, especially with regard to policy decisions.

\section{Mortality in NHS hospitals}

According to an article in the Daily Telegraph [1] (accessed online on 25/04/2007), the George Elliot Hospital (the only hospital run by the George Elliot Hospital NHS Trust) may have been the most dangerous hospital in England during the 2005/6 financial year. This is because its Hospital Standardised Mortality Ratio (HSMR) was 1.43 , i.e. the number of patient deaths in this hospital was $43 \%$ higher than expected. In contrast, the hospital run by the Royal Free Hampstead Trust may have been the safest, since its HSMR was only 0.74 , i.e. the number of patient deaths in this Trust was 26\% lower than expected. The source of information in the Daily Telegraph was provided by an organization called Dr Foster Intelligence, which recently published a report entitled "How healthy is your hospital" [2], in which the performance of NHS Trusts was assessed against several indicators, such as post-operative mortality and emergency readmission. 
According to the Daily Telegraph, the George Elliot Hospital had problems in the areas of both finance and hospital infection, though the Royal Free Hospital seems to have its own problems too. Whilst we do not have any explanations for the higher than average mortality rate in the George Elliot Hospital NHS Trust, we know that it is a relatively small hospital with only 352 beds, and admissions totalled 42,577 during 2005/6, according to Hospital Episode Statistics [3]. Even the Royal Free Hampstead Trust is not very large, with around 900 beds in current use for patient care, with total admissions of 62,062 during 2005/6 [3]. In contrast, the Leeds Teaching Hospitals NHS Trust has three hospitals and 2,370 beds (according to the Daily Telegraph website) with a total of 190,604 admissions during 2005/6 [3]. There is clearly huge variation in the sizes of Trusts and hence the number of patients they treat, and the question we consider is does size matter? We shall explain in this article why, from a statistical viewpoint, the size of a hospital may be a crucial factor as to whether or not that hospital appears at the top or the bottom of any league table.

\section{Why size matters}

First let us use a simple example to illustrate why the size of a hospital can matter. Suppose hospitals in England have only five different sizes - 200, 400, 600, 800 and 1000 beds - and they undertake 100, 200, 300, 400, and 500 coronary artery bypass graft operations each year, respectively. Also suppose that the post-operative mortality rate is nominally $10 \%$, irrespective of hospital size. The expected number of deaths for the different sized hospitals should then be $10,20,30,40$, and 50, respectively. Nevertheless, it is inevitable that across the years there will be some variation; for instance, in some hospitals with 200 beds only 8 patients may die, whilst in other hospitals of the same size 12 patients may die. The overall average mortality rate nevertheless remains $10 \%$. Suppose the extent of variation (standard deviation) between hospitals of the same size is similar across all hospitals, e.g. the observed number of deaths plus or minus its standard deviation is $10 \pm 3,20 \pm 3,30 \pm 3,40 \pm 3$, and $50 \pm 3$, respectively. So what of the observed mortality rates? From the smallest to largest hospital, the observed mortality rates have $95 \%$ confidence intervals of $4.0 \%-16.0 \%$, $7.0 \%-13.0 \%, 8.0 \%-12.0 \%, 8.5 \%-11.5 \%$, and $8.8 \%-$ $11.2 \%$, respectively. If we were to make a league table for these hospitals, the smaller hospitals are more likely to be found at the bottom and the top the league table. Nevertheless, if factors related to the success of coronary artery bypass surgery act in a similar way across different sized hospitals, then variations in the number of deaths for larger hospitals would be expected to be greater than for smaller hospitals.
Many factors affect the performance indicators of hospitals, such as the post-operative mortality rate. There has been a continuing debate regarding whether or not these indicators can really measure the quality of healthcare provided by a hospital Trust [4-9]. Any hospital that treats more patients with higher risks or greater complexity may show higher mortality rates. However, notwithstanding the controversy regarding the validity of performance indicators, it is important to note that the extent of variation in the number of deaths in hospitals of the same size is not in proportion to the size of the hospital, but is in proportion to the square root of its size $[10,11]$. Therefore, for our simple example, if all the factors related to post-operative mortality (e.g. case-mix, staff experiences, and support from post-operative care units, etc.) were comparable for all hospitals and operated in similar ways across hospitals of different sizes, the variation of the observed number of deaths would be $10 \pm 3.0,20 \pm 4.2$, $30 \pm 5.2,40 \pm 6.0$, and $50 \pm 6.7$, rather than $10 \pm 3.0,20$ $\pm 6.0,30 \pm 9.0,40 \pm 12.0$, and $50 \pm 15.0$. The observed mortality rates would then have $95 \%$ confidence intervals of $4.0 \%-16.0 \%, \quad 5.8 \%-14.2 \%, 6.5 \%-13.5 \%, \quad 7.0 \%-$ $13.0 \%$, and $7.3 \%-12.7 \%$, respectively. Hence, the smaller hospitals are still more likely to be found at the bottom and the top the league table.

From a statistical viewpoint, this is because the standard deviation of the sampling distribution of the mean, i.e. the standard error of the mean, is inversely related to the square root of the sample size: $\sigma_{\bar{x}}=\sigma / \sqrt{n}$. This equation appears in every introductory statistics textbook and was first stated by the French mathematician de Moivre in 1730. This equation shows that the greater the sample size, the less likely is the sample mean to fluctuate, i.e. the variation is much greater for small hospitals and much less for large hospitals.

It has been noted in the literature that there is "over-dispersion" of performance indicators for smaller hospitals or Primary Care Trusts [7], and therefore the use of league tables for the ranking of hospital performance may be misleading $[4,5,7,12]$. Quality control charts $[4,8]$ and funnel plots $[5,7,12,13]$ have been proposed as alternative strategies to compare hospital performance, and to identify those for whom performance is below the national standard. To understand why quality control charts and funnel plots are more appropriate methods for comparing the performance of hospitals, it is crucial for health services researchers, doctors, and patients to appreciate fully the significance of de Moivre's equation. 


\section{Throwing the die of death}

Suppose there is an imaginary fair die with 20 surfaces. One surface of the die is black and the other 19 are white. When the die is thrown, the probability of the black surface showing is 0.05 , i.e. when the die is thrown 20 times, we expect on average to see the black surface only once. However, due to the nature of all random processes, in each round of 20 throws the black surface may or may not show, or might show more than once. Similarly, although the black surface is expected to show 50 times when the die is thrown 1,000 times, the black surface may actually show more or less than 50 times. From a statistical viewpoint, an experiment like this is known as a Bernoulli trial $[14,15]$. The results collected from performing multiple independent Bernoulli trials, such as throwing our twenty-sided die 1,000 times, follow a binomial distribution $[14,15]$, which can be used to calculate the variation in the number of times the black surface is expected to show. By denoting the number of throws (trials) as $n=$ 1,000 and the probability of obtaining black as $\pi=0.05$, statistical theory tells us that the population mean, $n \pi$, is 50 and the standard error of this mean, $\sqrt{n \pi(1-\pi)}$, is 6.9 [10]. Consequently, the number of times the black shows has a $95 \%$ confidence interval of 36 to 64 .

In 2002-2003, the average mortality following selected surgical procedures in English NHS hospital Trusts was around 5\% [16]. Now suppose the die represents the probability of death following these selected surgical procedures and $n$ is number of surgeries undertaken by the hospital. The $95 \%$ confidence interval for the number of deaths is between 36 and 64, i.e. the mortality rate has a 95\% confidence interval between $3.6 \%$ and $6.4 \%$. For NHS hospital Trusts undertaking 4,000 surgeries, the expected number of deaths is 200 and the standard error of the mean is 13.8 , which is twice as large as that for hospital Trusts undertaking only 1,000 surgeries. However, the $95 \%$ confidence interval for the mortality rate of this larger hospital Trust is $4.3 \%$ to $5.7 \%$, which is narrower than that for the hospital Trust undertaking only 1,000 surgeries.

A funnel plot in Figure 1 shows a simulated dataset of 1,000 hospitals in which the number of surgical procedures $(\mathrm{Y})$ in each year has a mean of 2,500 and a standard deviation (SD) of 700. The mortality rate is assumed to be $5 \%$ across all sizes of hospital, so the number of expected deaths (X) has a mean of 125 and SD of 35. A random variable with zero mean and SD proportional to the square root of $\mathrm{X}$ is simulated to represent the variation/fluctuation in the observed mean number of deaths, and this is added to $\mathrm{X}$. The vertical axis in Figure 1 is the ratio of

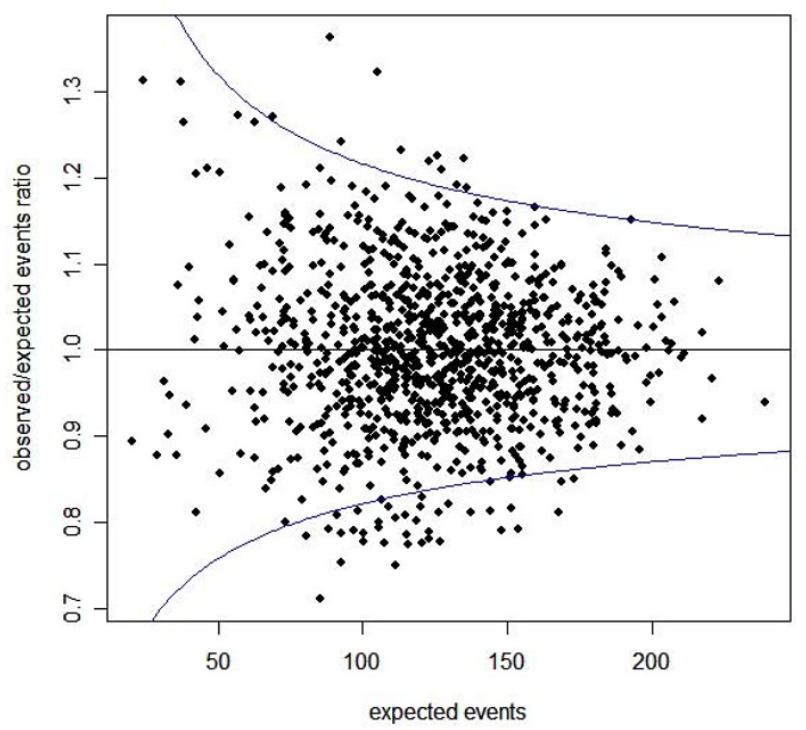

Figure I

A funnel plot of the relationship between the expected number of events and the ratio of observed to expected number of events in the simulated dataset of I,000 hospitals. The blue lines (top and the bottom of the panel) represent respectively the upper and lower $95 \%$ confidence limits of the observed/expected ratio.

observed number of deaths $(Z)$ over the expected number of deaths (X), and the horizontal axis is X. If we fit a linear regression model to the data, the regression slope will be close to zero, indicating that the observed to expected ratio is independent of the expected number of deaths (i.e. hospital size), yet variation in the $95 \%$ confidence interval of these ratios (represented by the blue lines both top and the bottom of the figure) is inversely related to hospital size. Although this simulation assumes no relationship between mortality and the number of surgeries undertaken, a few hospitals are below the lower confidence limit or above the upper confidence limit, as would be expected due to chance alone $5 \%$ of the time, indicating that their performance is either alarmingly poor or extremely good. We would therefore still need to be cautious in identifying the poor or good performers using funnel plots or quality control charts, given that chance is involved. In the report published in the "How healthy is your hospital?" readers can find that the report's graphs follow a very similar pattern [2].

\section{The most dangerous equation}

In a recently published article [10], Howard Wainer nominated de Moivre's equation as "the most dangerous equation", since being ignorant of its consequences may cost 
us dearly, especially with regard to policy decisions. One example given by Wainer was the project to convert large schools to many small schools simply because, amongst the high-performance schools, there seemed to be an unrepresentatively large proportion of small schools. The Bill and Melinda Gates foundation had given approximately $\$ 1.7$ billion for this project, which achieved disappointing results [10]. Maybe it should be called the most expensive equation? If someone in the foundation had noted that small schools were also over-presented in the poor-performance schools, this $\$ 1.7$ billion could have been saved for other purposes.

Returning to hospital performance league tables, Table 1 shows the best and poorest performing NHS hospital Trusts, amongst the 152 English NHS Trusts, with respect to the hospital standardised mortality ratio (HSMR) for 2005/6, provided by "How healthy is your hospital" [2]. The number of hospital admissions within each hospital Trust during 2005/6 is used as a proxy variable for the volume of patients treated within each hospital Trust [3]. The range of admissions was between 24,269 and 232,033. Sixty-nine of the $152(45.4 \%)$ Trusts had fewer than 65,000 admissions and 13 of them appear in Table 1; none of the 27 Trusts with admissions greater than or equal to 110,000 appears in Table 1 . We may conclude that there is an unrepresentatively large proportion of small Trusts in both the best and poorest performing groups. Figure 2 shows the relationship between HSMR [2] and the number of hospital admissions [3] for the 152 English NHS hospital Trusts listed in "How healthy is your hospital" [2]. It is noted that there is less variation amongst mortality rates the greater the number of admissions, as predicted by de Moivre's equation, and this explains, in part, why many hospital Trusts in the league table (Table 1) are small ones. Figure 2 also shows that the
HSMR of many NHS hospital Trusts is outside the $95 \%$ or even $99 \%$ confidence interval. Although the HSMRs of several large-sized NHS Trusts are relatively lower than those of many small Trusts, the HSMRs of these largesized NHS Trusts are still above the upper 99\% CI. However, although this may indicate the performance of these large NHS hospital Trusts is also below the bar, these Trusts would not be identified by the league table.

Why the George Elliot Hospital Trust had the highest mortality rate in the England in 2005/6 merits further explanation, but it might be too early to call it the most dangerous hospital based simply on its HSMR. As long as it remains small, it is more likely than larger hospital Trusts to be at the bottom or the top of any league table, even if the quality of care provided by the George Elliot Hospital Trust is no worse than other Trusts [9]. This is not to imply that only the size of a Trust plays a role in the random processes of variation; some studies have suggested that there exists an inverse association between hospital (surgeon) volume and surgical mortality $[17,18]$. In addition, there may be other important managerial and financial factors contributing to the poorest (or best) performance of some (small) hospitals. Nevertheless, using league tables to rank the performance of hospital Trusts could be potentially misleading, and there are alternative, more appropriate methods available $[4-8,12,13]$. Therefore, the next time we hear about the 'most dangerous/safest' city, the 'most dangerous/safest' postcode, the 'best/poorest' school etc., it is better to think again about de Moivre's equation.

\section{Competing interests}

The author(s) declare that they have no competing interests.

Table I: Best and poor performing NHS Trusts based on hospital standardised mortality ratios for 2005/6 according to "How healthy is your hospital"; the information pertaining to the number of admissions in 2005/6 is obtained through the website of Hospital Episode Statistics (accessed on 21/07/2007).

\begin{tabular}{|c|c|c|c|}
\hline Best performing NHS Trusts & $\begin{array}{l}\text { Number of } \\
\text { admissions }\end{array}$ & Poorest performing NHS Trusts & $\begin{array}{l}\text { Number of } \\
\text { admissions }\end{array}$ \\
\hline Royal Free Hampstead NHS Trust & 62,062 & $\begin{array}{l}\text { University Hospitals Coventry and Warwickshire NHS } \\
\text { Trust }\end{array}$ & 92,222 \\
\hline The Hammersmith Hospitals NHS Trust & 95,026 & Tameside and Glossop Acute Services NHS Trust & 43,097 \\
\hline Bradford Teaching Hospitals NHS Foundation Trust & 101,540 & $\begin{array}{l}\text { Basildon and Thurrock University Hospitals NHS } \\
\text { Foundation Trust }\end{array}$ & 62,418 \\
\hline St George's Healthcare NHS Trust & 82,043 & Dudley Group of Hospitals NHS Trust & 78,036 \\
\hline Cambridge University Hospitals NHS Foundation Trust & 109,204 & The Medway NHS Trust & 60,698 \\
\hline Homerton University Hospital NHS Foundation Trust & 44,652 & Mid Staffordshire General Hospitals NHS Trust & 53,312 \\
\hline Guy's and St Thomas' NHS Foundation Trust & 103,627 & Burton Hospitals NHS Trust & 48,324 \\
\hline St Mary's NHS Trust & 56,244 & Good Hope Hospital NHS Trust & 59,487 \\
\hline $\begin{array}{l}\text { The Royal Liverpool and Broadgreen University } \\
\text { Hospitals NHS Trust }\end{array}$ & 64,135 & Kettering General Hospital NHS Trust & 63,558 \\
\hline Weston Area Health NHS Trust & 25,434 & George Eliot Hospital NHS Trust & 42,577 \\
\hline
\end{tabular}




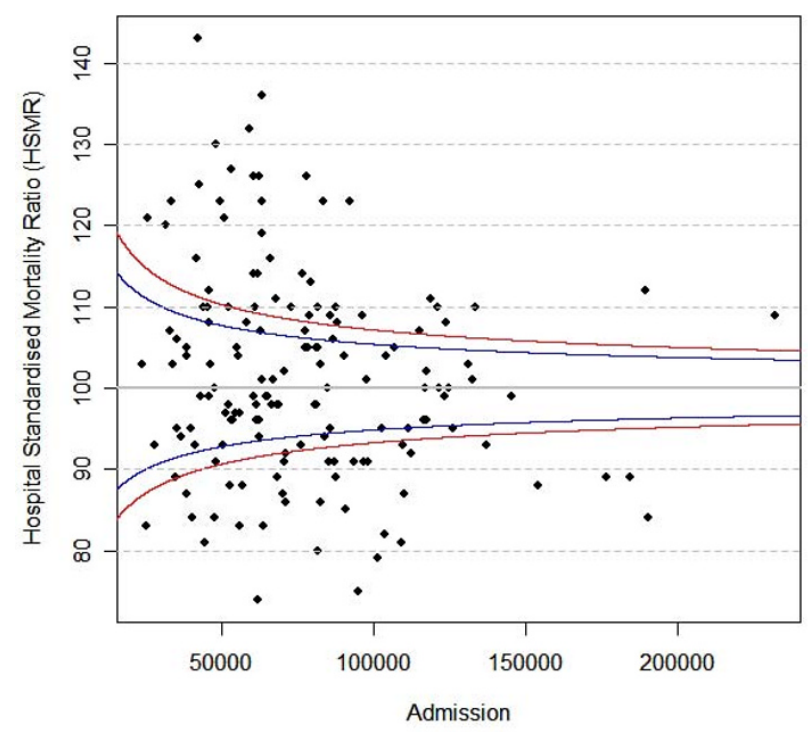

Figure 2

The relationship between the number of admissions and Hospital Standardised Mortality Ratio (HSMR). The variation in HSMR is inversely related to the number of admissions. The blue lines (top and the bottom of the panel) represent respectively the upper and lower $95 \%$ confidence limits of the HSMRs. The red lines (top and the bottom of the panel) represent respectively the upper and lower $99 \%$ confidence limits of the HSMRs.

\section{Authors' contributions}

YKT conceived the ideas of this study, obtained and analysed the data, and wrote the first draft. MSG contributed to the discussion of the statistical analyses and revisions of the draft. Both authors read and approved the final manuscript.

\section{Acknowledgements}

We would like to thank the three reviewers for their very helpful comments and suggestions which help improve this article greatly. Both authors are funded by the United Kingdom government's Higher Education Funding Council for England (HEFCE). YKT is also supported by the UK Research Council fellowship.

\section{References}

I. The Daily Telegraph website [http://telegraph.co.uk/news/ main.jhtml? xml=/news/2007/04/24/nhs24.xml]. Accessed on 26 April 2007

2. Dr Foster Intelligence. How healthy is your hospital? [http:/ /www.drfosterintelligence.co.uk/hospitalguide/index.asp]. Accessed on $25 / 04 / 06$

3. Department of Health, Hospital Episode Statistics website [http://www.hesonline.nhs.uk/Ease/servlet/Content Server?sitelD=1937\&category|D=212]. Accessed on 2I July 2007

4. Mohammed MA, Cheng KK, Rouse A, Marshall T: Bristol, Shipman, and clinical governance: Shewhart's forgotten lessons. Lancet 200I, 357:463-67.
5. Spiegelhalter DJ: Mortality and volume of cases in paediatric cardiac surgery: retrospective study based on routinely collected data. BMJ 200I, 323:I-5.

6. Gibberd R, Hancock S, Howley P, Richards K: Using indicators to quantify the potential to improve the quality of health care. International Journal for Quality in Health Care 2004, I6(Supplement I):i37-i43.

7. Spiegelhalter DJ: Handling over-dispersion of performance indicators. Quality and Safety in Health Care 2005, I 4:347-35 I.

8. Marshall T, Mohammed MA: Case-mix and the use of control charts in monitoring mortality rates after coronary artery bypass. BMC Health Services Research 2007, 7:63.

9. Pitches DW, Mohammed MA, Lilford RJ: What is the empirical evidence that hospitals with higher-risk adjusted mortality rates provide poorer quality care? A systematic review of the literature. BMC Health Services Research 2007, 7:91.

10. Wainer $\mathrm{H}$ : The most dangerous equation. American Scientist 2007, 65:249-256.

II. Kirkwood B, Sterne JAC: Essential medical statistics 2nd edition. Oxford: Blackwell Science Ltd; 2003.

12. Spiegelhalter DJ: Problems in assessing rates of infection with methicillin resistant Staphylococcus aureus. BMJ 2005, 331:1013-1015.

13. Spiegelhalter DJ: Funnel plots for comparing institutional performance. Statistics in Medicine 2005, 24: I I85-I 202.

14. Rice JA: Mathematical statistics and data analysis 2 nd edition. Belmont: Duxbury Press; 1995.

15. Gill J: Essential mathematics for political and social research New York: Cambridge University Press; 2006.

16. Commission for Health Improvement: Deaths within $\mathbf{3 0}$ days of selected surgical procedures. 2003 [http://www.chi.nhs.uk/Rat ings/]. (accessed July 2007)

17. Birkmeyer JD, Siewers AE, Finlayson EVA, Stukel TA, Lucas FL, Batista I, Gilbert Welch HG, Wennberg DE: Hospital volume and surgical mortality in the United States. New England Journal of Medicine 2002, 346: I I28-I I37.

18. Birkmeyer JD, Stukel TA, Siewers AE, Goodney PP, Wennberg DE, Lucas FL: Surgeon volume and operative mortality in the United States. New England Journal of Medicine 2003, 349:21।7-2I27.

\section{Pre-publication history}

The pre-publication history for this paper can be accessed here:

http://www.biomedcentral.com/1472-6963/7/185/pre $\underline{\mathrm{pub}}$

Publish with Biomed Central and every scientist can read your work free of charge

"BioMed Central will be the most significant development for disseminating the results of biomedical research in our lifetime. " Sir Paul Nurse, Cancer Research UK

Your research papers will be:

- available free of charge to the entire biomedical community

- peer reviewed and published immediately upon acceptance

- cited in PubMed and archived on PubMed Central

- yours - you keep the copyright 